\title{
Business Intelligence and Absorptive Capacity of Information by Wineries in the Provence Wine Industry
}

\author{
Coralie Haller ${ }^{1}$, Serge Amabile ${ }^{1}$, Regis Meissonier ${ }^{2} \&$ Stephane Boudrandi $^{3}$ \\ ${ }^{1}$ CERGAM (Centre d'Etudes et de Recherche en Gestion d'Aix-Marseille), Aix-Marseille University, France \\ ${ }^{2}$ Professor of Information Systems, Université Picardie Jules Verne, France \\ ${ }^{3}$ Director of the Business Intelligence Center, Institute of Political Studies ("Sciences Po"), Aix en Provence, \\ France
}

Correspondence: Serge Amabile, Professor of Information Systems, CERGAM, Aix-Marseille University, France. E-mail: serge.amabile@univ-amu.fr

$\begin{array}{ll}\text { Received: May 25, } 2012 & \text { Accepted: June 7, } 2012 \quad \text { Online Published: December 31, } 2012 \\ \text { doi:10.5539/ibr.v6n2p126 } & \text { URL: http://dx.doi.org/10.5539/ibr.v6n2p126 }\end{array}$

\begin{abstract}
Purpose: By referring back to researches relative to the "Absorptive Capacity", this article examines the way in which the actors' capacity of attention is distributed among various business intelligence systems. Design/methodology/approach: A qualitative research has been conducted with sixteen organizations in the Provence wine industry. Findings: Results reveal that these wineries give only little attention to information coming from professional organisms. However, they favor information collected through formal and informal relations they maintain in their current activity with other companies of industry. Practical implications: The discussion part associates the results with the model of ACAP. The information sources absorption by the wineries is the consequence of their "experience" with other actors of their environment (suppliers, customers, competitors, etc.), rather than the consequence of integration mechanisms set up by the professional organisms.
\end{abstract}

Keywords: business intelligence, absorptive capacity, Provence wine industry

\section{Introduction}

Researches conducted on the relation between information and decision and on business intelligence have been referring back to problems of overabundance of information perceived by the actors with regard to their own processing capacities (March \& Simon, 1958; Simon, 1969; Ansoff, 1975). From then on, this descriptive overabundance of information is seen as a "threshold" beyond which a person does not any more succeed in discriminating, in the mass of available information, the one which can be perceived as relevant for complex problem solving. In order to improve mass information processing, it has been suggested to use "intelligent filters" (Simon, 1969, Amabile \& Guechtouli, 2008). Other researches focused more on "organizational substitutes" which correspond to side processes with peers and experts (Galbraith, 1974), modes of coordination inter-units (Tushman \& Nadler, 1978), or networks of attention (Amabile, 1999). As March (1991) and more recently Ocasio (1997) indicated, there are only a few researches which are looking at how an organization's absorptive capacity is distributed among different business intelligence systems.

Lane and Lubatkin (1998) recognized that an organization's capacity to absorb new knowledge differs in regards to the origin of the knowledge. This situation is even more relevant as when an organization takes part of an industry in which there are number of business intelligence sources, all different in essence and form. In fact, it is possible to find professional organisms (consular agencies, professional unions, associations, councils, etc,) which develop and propose business intelligence activities related for example, to economic and business trends, market trends, etc. At the same time, companies maintain cooperative exchanges about their professional practices with other organizations in their industry (customers, suppliers, partners, competitors, etc.).

The study specifically builds upon researches on the ACAP model (Cohen \& Levinthal, 1990; Zahra \& George, 2002; Todorova $\&$ Durisin, 2007). A qualitative approach is used to analyze in-depth interviews conducted with 14 wineries of the Provence wine region. Results reveal that these wineries give only little attention to information coming from professional organisms. However, they favor information collected through formal and informal relations they maintain in their current activity with other companies of industry. 
The discussion part associates the results with the model of ACAP. Our study suggests that the information sources absorption by wineries is the consequence of their "experience" (Zahra \& George, 2002) with other actors of their environment (suppliers, customers, competitors, etc.), rather than the consequence of the integration mechanisms set up by the professional organisms. Companies multiply and articulate the information sources coming from various organizations presenting a more or less important level of "similarity" (Lane \& Lubatkin, 1998). The article concludes that even if this "similarity" influences the level of absorption of information and knowledge, it cannot be explained by the cognitive, cultural or organizational properties of the transmitters of the information. The business intelligence activity is maybe based, before all, on the capacity of the receiver to combine them, and to enhance the interpretations which can be made.

\section{Literature Review}

The management literature about organizational learning is widely spread over different themes, like information gathering (Gray \& Meister, 2004), new product development (Mitchell, 2006) intra (Argyris, 1976 ; Nonaka, 1994 ; Malhotra, 2005) and inter organizational changes (Arikan, 2009). The absorptive capacity model (ACAP: Absorption CAPabilities) proposed by Cohen and Levinthal (1990) offers an analytical frame which allows to integrate various stages of the process. Absorptive capacity is defined as the ability for a company to evaluate, assimilate and exploit new knowledge. Focused on how cognitive structures of organizations evolve, the model aggregates organizational and rational dimensions participating to this process. Because of its multipurpose character, the model has been used in different areas like intra-organizational (Cohen \& Levinthal, 1990 ; Zaheer \& Bell, 2005) and inter-organizational learning (Lane \& Lubatkin, 1998 ; Van Den Bosch et al., 1999 ; Reagans \& McEvily, 2003). In 2011, Lewin et al. (2011) revealed that Cohen \& Levinthal's model has been cited over 10 000 times in articles, books and chapters. However, a large majority of the empirical studies concentrated only on tangible results from the absorptive capacity, organizational and inter-organizational conditions remaining under explored (Volberda et al., 2010). In regards to our knowledge, it seems that the ACAP model has not been used with the aim to extend the analysis of business intelligence over the only process of surveillance of signals from the environment.

\subsection{Business Intelligence, Assimilation and Transformation}

Taking into account March and Simon's observations (1958) on decision making processes, and referring back to the literature in psychology (Bower \& Hilgard, 1981) on learning process, Cohen and Levinthal (1990) assume, in their model that the enterprise's existing knowledge play an important role in its capacity to understand and evaluate new sources of external knowledge. Besides, they argue that the more a company has an important and diversified knowledge base, the more it will be able to relate and absorb new knowledge. (cf. p. 131). However, Henderson and Clark, (1990) and Leonard-Barton, (1992) go further and underline that number of companies have difficulties absorbing knowledge perceived as dissonant with their existing cognitive structure. Actors tend to reinterpret and distort those signals in order to reduce their perceived dissonance. These appropriation processes cause inertia of the company's existing knowledge (path dependance) which can influence how new knowledge are evaluated (Todorova \& Durisin, 2007, p. 777).

Considering that change in cognitive structures takes time and requires intellectual efforts from individual, Cohen and Levinthal (1990, p. 131) have introduced "assimilation" as an incremental learning process of new knowledge. In their literature review about absorptive capacity, Zahra and Georges (2002) added the notion of "transformation" (p. 188) as an additional and consequent stage to the notion of "assimilation" of new knowledge. According to them, organizations transform their cognitive structure when they did not manager to assimilate new knowledge. In fact, the company will modify its routines in order to facilitate the combination of new knowledge with existing ones. The transformation changes the character of the knowledge into a "bisociation" process which corresponds to the capacity of the actors to build a new cognitive scheme from two set of knowledge, perceived at the beginning as incompatible (p. 190). In this perspective, Winter (2000) specifies that there are "triggers" which he defines as, events likely to encourage or dissuade a company to answer an internal or external stimulus. They can correspond to a new external (emergence of new direct or indirect competitors, new regulations, random events, etc.) or internal situation (lack of performance, social crisis, merger, acquisition, etc.) which requires company to react. Even if the economic crisis represents a Schumpeterian vision of the creative destruction process, it can encourage a company to develop its efforts and acquire new knowledge and competences (Huber, 1991).

Considering Cohen and Levinthal (1990)'s model, Lane and Lubatkin (1998) acknowledged the importance of existing knowledge in the capacity for a company to distinguish and value a new knowledge. Though, in an inter-organizational context, the authors indicate that the existing "similarity" between these companies is an 
important factor in the absorption of knowledge exchanged between them. Indeed, they observe that companies have more ability to assimilate new knowledge coming from suppliers or partners having comparable organizational structures or management of information policies. In this way, the absorptive capacity of new knowledge would be "relative" (RACAP) to the properties of the entity from which it results.

However, companies differ in their ability to create value from new collected knowledge (Grant, 1996). Lane et al.'s (2006, p. 843-845) article reveals persistent inconsistencies, related to the hypothetical predictive character of the absorption capacity on the performance. The organizational complexity in which it is advisable to examine the concept, led Zahra and George (2002, p. 190) to make the distinction between "potential absorption capacity" (PACAP) and "realized absorption capacity" (RACAP). The aim was to understand the organizational factor of efficiency defined as the relationship between these two variables (op. p. 191). With regard to the initial model of Cohen and Levinthal, the first one corresponds to the capacity of the company to acquire and value knowledge without guarantee of the exploitation (Zahra \& Georges, 2002, p. 190). The second one is, on the other hand, function of the capacities of transformation (op. P. 190).

So in this research, we concentrate on the potential of absorption of knowledge of the company related to its business intelligence activities, without trying to predetermine what can be the hypothetical significant impacts in terms of valuable creation for the company. In this purpose, we consider factors of influence of the ACAP which are, according to our own analysis, the most relevant in a company's industry: (1) the social mechanisms of integration; (2) the experience of the enterprise and similarity among actors.

\subsection{The Social Mechanism of Integration}

The social mechanisms of integration can be defined as a set of processes and routines which facilitate the interaction and knowledge sharing in an intra-organizational (Brown \& Duguid, 1991; Nonaka, 1994) and inter-organizational context (Kogut, 2000). They influence the company's absorptive capacity in a formal way, for example, by using coordinators; or in an informal way, for example by using a social network (Reagans \& McEvily, 2003; Zaheer \& Bell, 2005). With the aim to reduce the resistance to knowledge sharing, they can improve the assimilation and transformation the company's capacities (Zahra \& George, on 2002, p. 194). They can also structure the company's business intelligence system by influencing, upstream, the capacity of the company to identify sources of information and strategic knowledge (Todorova \& Durisin, 2007, p. 781).

In the context of a wine industry, the professional organisms are in charge of the surveillance of the economic environment for their members (wineries, traders, etc.). For that purpose, they use several social mechanisms of integration to insure the distribution of collected information and knowledge: colloquiums, newsletters, comities, meetings, etc. According to their sensibility, culture and priority, the subcategories of actors of a company can have various levels of knowledge absorption. This is a "top down" structured and organized business intelligence activity, according to which we can formulate the following proposal:

Proposal 1: The potential absorption of information by a company is encouraged by the social mechanisms of integration of the industry it takes part.

However, the literature emphasized more informal business intelligence processes, which can be fed by companies' relations with other economic actors of their environment (client; suppliers, competitors, ...) This activities correspond to the "experience" mechanism of the ACAP model.

\subsection{The Company's "Experience" and "Similarity" among Actors}

The "experience" of the company should not be considered as its general know-how in its activity sector. In the absorptive capacity model, enterprises are supposed to develop their experience in contact with specific information and knowledge emerged from their relationships with customers, competitors, partners, etc. (Zahra $\&$ George, 2002, p. 193). These experiences allow a company to develop new routines (Nelson \& Winter, 1982) susceptible, in return, to influence targets of research for new knowledge. Indeed, companies seem to gather information in areas where these searches were profitable in the past (Cyert \& March, 1963). If some of these experiences can be the consequence of predetermined projects (in case of partnerships or strategic alliances for example), most appear in the course of the current interactions of a company with its customers, suppliers or competitors (Levitt \& March, 1988). So, unlike the type of the business intelligence activity described for proposal 1, it is here about a search of information conducted by the company in an active manner, on its own focal of attention.

On the other hand, collected information results from organizations having certain points in common with the receiving company (same business sector, cultural and geographical nearness, etc.). Following the observations of Lane and Lubatkin (1998), we can then suppose that, this level of similarity between the "parent company" 
and the "receiving company" is going to favor the absorption capacity of the second one. In fact, companies which have close business, structural and cultural references, have common bases facilitating interorganizational learning (Lane \& Lubatkin, 1998; Arikan, 2009).

Finally, the fact that these informal business intelligence mechanisms can be conducted in current relationships of a company, allows taking into account the possible combination of exploitation and exploration activities (March, 1991).The literature recognizes that companies often tend to concentrate their resources on achieving their current activity rather than on developing it (Amabile, 1999).The trap is then to persistently specialize, conform and reproduce the same plans (Nystorm \& Starbuck, 1984, p. 59) and to become inadvertent to its own progressive maladjustment (Amabile, 1999). Among the possible reasons which could explain this behavior, we could suggest the lack of financial or material resources. This cannot be considered as a satisfactory explanation as the literature demonstrated, for a long time, that the information was not any more a rare resource and difficult to acquire (Simon, 1969). On the other hand, in an economic world, where time is a variable "to overcome" (Stalk, 1993), the question of temporality in the mechanisms of coordination becomes a strong element of the general functioning of organizations. To participate in a professional colloquium can be a conflicting decision which can not fit into an overloaded work agenda. The gathering of information on new business practices will often be done on the remaining spare time. However, conducting business intelligence activities with its customers or suppliers, while handling with them current business can be compared to "hidden time" work which allows combining exploitation and exploration. The fact that collected information and knowledge are directly related to both the activity of the company and other actors in the environment, leads us to suggest the following proposal:

Proposal 2: The potential absorption of information by a company is encouraged by its own experience in the framework of its current activity with economic actors of its environment with whom their share sufficient similarity.

\section{Case Study}

\subsection{A Complex and Fragmented Context of Research}

Our research focuses on wineries in the Provence wines industry. This regional industry is part of the French wine industry, which has an economic and commercial importance. According to Hannin et al (2010), the weight of the wine in the balance of trade can be approximately compared to "hundred of Airbus". (p. 10). Representing around 6.3 billion $€$ in 2008 against 5.5 billion $€$ in 2003, the wine business is the first contributor of the French food-processing foreign trade. In this context, the rosé wine in France counts for approximately $11 \%$ of the volumes, what corresponds to an estimation of 11000 direct jobs, and 66000 indirect jobs. Wine growing is at stake in the Provence regional economy, with 23000 hectares in production, a turnover of $400 \mathrm{M} €$ upstream the value chain and $650 \mathrm{M} €$ down-stream the value chain (Flanzy, C. et al., 2009).

In order to understand the challenges faced by the Provence wine industry, it is necessary to consider the global context of the wine industry. Wine consumption has increased over the last years after a drop of several decades. It is pulled by countries called "new consumers countries", while consumption in the "traditional" countries (producers of Europe) continues to fall. The world consumption differs according to the types of wines and to the different producers with various strategic behaviors (pro-active, followers, etc). So, the market of wines tends to redistribute quickly in spite of the inertial character of a long-lasting plantation (plantation 5 years before production, which lasts then between 25 and 100 years. (Flanzy, C. et al., 2009). We observe that the world vineyard is in contracting under the main influence of the European continent, due to the subsidized pulling out implemented in 80 s. Over thirty years, the world vineyard lost $25 \%$ of its surface, the European continent $30 \%$ and the European Union 34\%. However the trends are contrasted between 1994 and 2009, with a growth of the wine surfaces in the new world and a regression in Europe (Hannin et al., 2010).

Nevertheless the rosé wine remains a dynamic market with an increasing demand, and becomes an important element of the wine in the world, in terms of production, consumption (with $9 \%$ of the volumes of wine consumed in the world in 2006) and of economic exchanges (Flanzy, C. et al., 2009). In this context, the situation of Provence wines takes on a specific character, as far as $88 \%$ of the produced volumes of wine are Rosé wine. Because of its leadership position in the production of rosé wines AOP (protected label of origin) (Note 1), with about $40 \%$ of the French production in 2009, the Provence region is one of rare wine-producing regions not to suffer from, what is qualified as crisis in the other vineyards.

In spite of a favorable economic context for the Rosé wine, the wine sector is in total transformation, in particular on the international stage. Thus wineries have to face a certain number of challenges (Hannin et al., 2010). 
They have to take into account not only the emergence of mass marketing and changes in consumption practices but also the important competitive density and the strict legislation, which differs from one country to another, when producing and selling their wines. Other constraints, more local can be added, such as difficulties of settling down and transmission, land pressure or soils constraints (irrigation in particular). It appears to be necessary for the wineries of the Provence wine industry to be aware of their environment to be able to understand and anticipate strategic issues they are facing or will be facing in the coming future.

Besides, these wineries evolve within a local sector which is characterized by an inter-organizational complex and fragmented context including various regional entities called professional wine organizations (OPV). Wine councils (AOP: appellation of certified origin and IGP: protected geographic indication), appellations labor unions, federations of independent wine growers and cooperative cellars, associations of "terroir" and public administrations are brought to exchange economic and declarative information, knowledge, know-how and innovations, but also to communicate information to their members. In this context, an organism with regional vocation, the Provence Wine Council (CIVP) is commissioned to lead various axes of development of the sector. The CIVP represents both professionals of wine production and of wine trading. There are wine producers (wineries and cooperative cellars) of three major appellations: Côtes de Provence, Coteaux d'Aix-en-Provence and Coteaux Varois en Provence, as well as the regional federation of the trade. The general objective of the CIVP, defined by statutory missions, is to gather and share means to increase weight of the wine sector, to value specificities and characters of every "terroir" through the implementation of interregional projects.

\subsection{Methodological Positioning and Data Collection}

In this context, our research aims at understanding social and managerial mechanisms connected to the management of the existing informative flows between actors within the regional industry. It is a matter of experimenting and investigating the complex context of information management in this sector, to proceed to a real immersion within organizations to be able to structure a "system of observation to produce of sense" (Charreire Petit \& Durieux, 2007, p. 61). We decided to follow the recommendation of Miles and Huberman (2003) who suggest the adoption of a qualitative methodology as it presents numerous advantages for a study of in-depth phenomena. In that purpose, we used a specific approach of the action-research method, the interaction-research method which is based on multiple interactions between the researcher and practitioners and regular round trips between the practice and the theory, the empirical and the abstract. The researcher worked in close collaboration with various actors of the industry in order to elaborate and implement synergies in the management of information at a regional level. The challenge was to build a reliable relationship with various interviewees and to adapt to the person and to the situation at stake. According to Van Maanen (1983, p.110), this reliable relation appears "in particular contexts when the researcher demonstrates an understanding of the reality at stake". We adopted an "empathic" position with wine growing estates and a more "distant" position with the professional wine organizations. These approaches allowed the researcher to approach the wine industry from the inside and to acquire the necessary knowledge to grasp specific issues of the regional sector in a business context. The understanding of the Provence wines region complexity is thus partially based on the researcher's own knowledge of the local technical-economic environment acquired in professional situation. Experience of practitioners has been required in the appreciation knowledge produced by the researcher with the objective to co-construct actionable knowledge susceptible to influence practices from the real constraints of the ground (Avenier \& Schmitt, 2007).

Moreover, we chose to use a case-study approach which gives an important flexibility during the interactions with the field of research (Yin, 2009; Eisenhardt, 1989). Through a deep contact with the field of research, this method gives access to a wealth of data helping to understand current dynamics. In that matter, we collected our data according to Wacheux (1996): participating observations, informal discussions and semi-directive interviews. In that matter, we worked on a structured interview guide including strict instructions and targeted questions. It was elaborated to approach a series of themes defined beforehand in relation to the literature review. Two types of questions were used: the "main questions" which serve as introduction and the "investigation questions" intended to complete or clarify an incomplete or vague answer. The researcher is then a speech facilitator and a guide of the interviewees: the implication is "shared" (Blanchet \& Gotman, 1992).

\subsection{Definition of Sample of Research}

The sampling has been build gradually, according to our understanding of the sector and to its challenges. We chose to work with wineries members on the CIVP. These enterprises represent $28 \%$ of the total volumes of wine packaged and marketed, against $24 \%$ for the cooperative cellars (estimations CIVP, campaign in 2008/2009). Besides, with 650 particular cellars (for 40 cooperative cellars), they represent the majority of the 
actors for the Provence wine region. The definition of the research sample was made from a representative sample group of wineries belonging to the one three AOP represented in the CIVP and by taking into account, at the same time the number of staff and the production surface. Using this approach, a final list of nineteen wineries was thus established, which were being able to be sought for collaboration. At the end, the data collection is based on sixteen semi-directive interviews of one hour and thirty minutes each. The three remaining wineries were not available or felt little concerned about management of information flows within the Provence wine industry. This primary collection of data was completed by the consultation of internal and external documents and externs from each wine growing estate. The researcher then proceeded to the transcription of each of the semi-guided interview based both on audio recordings and notes on visual observations of the field of research. Besides, the interviewees had various exchanges with the researcher on the basis of a synthesis of 16 semi-conducted interviews sent before end. This approach allowed specifying certain themes of research and, in particular, to seize the complexity of the industry which consists of a multitude of structures operating within several networks.

The targeted interviewees were wineries' leaders, business managers, or their close co-workers (such as the maitre de chai or the oenologue). Most of the works led on SMEs or on very small SMEs (Julien, 1995) testify of the leader's strength over the whole of the processes of decision making. These actors can be identified as being the best persons to provide answers to questions regarding the management of information within the sector in general and within their winery in particular. Even if they are not always the main users of all the information, leaders are, at the same time in charge of the management of the organization and thus of its information system.

\subsection{The Data Analysis}

The data analysis was realized in two stages. At first, a lexical analysis was conducted with the software Sphinx Lexica to better grasp the wealth of the corpus through the analysis of the words' frequency of appearance and the repeated segments. The use of the software appeared as an important preliminary stage of the content analysis as it allowed bringing up themes of analysis on which we define categories. The second stage of the data processing consisted of a thematic analysis of the interviews based on a "general plan of coding". This plan is based on notions brought out by the lexical analysis of the corpus, on extracts of category-specific defined in the other studies and on the literature review (Hadly Rispal, 2002). We integrated both research questions, discovered and characterized several themes (efficiency, utility and information exchanges), to which we associated codes (Miles \& Huberman, 2003). The objective was to identify the presence or absence of themes in each of the interviews and to analyze the relations between the various categories. We chose to use matrices of "abstract groupings" and to proceed to a grouping of verbatims according to the research propositions of expressed previously (Miles \& Huberman, 2003).

\section{Results}

The absorptive capacity model of Cohen and Levinthal (1990) and its evolutions proposed by Lane and Lubatkin (1998) and Zahra and George (2002), Todorova and Durizin (2007) Lewin et al. (2011) allowed us to investigate the specific context of management of information by wineries of the Provence wine industry. More particularly, we analyzed how these wineries allocate their attention capacity between various systems of business intelligence to which they can be confronted.

As mentioned previously, the wineries evolve in a fragmented context in which coexist various entities. Regarding the results' analysis, wineries' leaders identify certain number of actors as being possible information sources within the industry and as playing a role in the management of the information. This multitude of interlocutors (from 3 to 7) asks the actors for declarative obligations and supplies them with a large number of information, often similar. Indeed, a wine grower located in the Côtes de Provence has the obligation to subscribe to the labor union of the Côtes de Provence, to the Provence Wine Council (CIVP) if he produces AOP wine and to the wine council for local wines if he produces IGP wines. Most of these actors are also members of a professional federation (even if it is not a legal obligation). In spite of, this plethora of professional organizations, wineries leaders manage to identify each of them, quoting their name and explaining their missions. Federations offer trainings, labor unions help wine growers to fulfill production specifications, and the Provence Wine Council proposes promotion and communication services on the French territory and in certain foreign countries. They also refer back to the technical centre of the rosé wine and to the agriculture Chamber.

"2 o 3 times per year, we receive a book from the technical center of rosé wine with specific studies. Each year, we are told about studies conducted on modes to make wines, yeast,..." (Leader 3)

"The third source of information is the newsletter of the Agriculture Chamber. They send it via the Internet. It is quite good and we do not need to print it. We can read it, and through to away" (Leader 13) 
Wineries leaders are also able to qualify the information coming from the professional organisms. In fact, they state receiving economic information (volumes of produced wines, price list of wines bulk, etc.), technical information (modes of wine makings), legal information (subsidy policy, plan of inspection, specifications, etc.) or, information related to international markets (volumes of production in specific countries). This information has a global dimension and concern long term situations.

Beyond the fact that actors identify the missions and certain types of information spread by each organism, the research puts in perspective a fuzzy management if information within the industry. About $80 \%$ of the leaders of wineries mention the existence of redundancy and profusion of information. The "same information is received three or four times" and even if they subscribe to different organisms, "it is to receive the same information at the end". Moreover, they perceive a profusion of information as "too much information" circulates. Leaders of wineries underline also that there are "too many people" and "one says one thing, one says it before, one says it after, and one says it as he wants, one modifies it; it's annoying". Besides, wineries leaders refer back to this information, as not related to the reality. It is unsatisfactory because too much reformatted by the OPV and thus "institutionalized". Indeed, verbatims indicates that these actors perceive a gap between their reality and the information passed on by the organisms: "we are not in the same vein". Overall, wineries leaders perceive the information spread as sparsely differentiated, insufficiently targeted or adapted to their needs.

"This information is not adapted to us, in terms of volume of wine sold, in terms of markets which we want to target. It does not correspond. How do you want to adapt the same information for a domain which makes 600 000 bottles and has three different vintages and for a domain which makes 60000 bottles and has a single range of product?" (Leader 3)

"I try to follow [this information] to have a small trend, to know how the market generally behaves and to have a global approach. Later, it is true that this information is not in accordance with our reality" (Leader 2)

"This information [economic] are not representative of what we see and what we live" (Leader 3)

"Numbers are great, but there is a reality behind, a business reality which is completely different from one to another" (Leader 5)

In a context of multiple spreading of information, wineries leaders are quickly overwhelmed. Precisely, the rhythms of distribution do not correspond to their work agenda: they relate a lack of time to assimilate information coming from the OPV. This impression is stressed by the fact that these actors assume, often, several roles within their company. It seems difficult for them to process "on the spot" information spread by the OPV. They express a dilemma between availability and processing of information. Oddly enough, if this information is not rejected in total, it is not perceived as a decision-making support for wineries but rather as a source of dispersal or an additional task to be supported in a busy schedule. Integration mechanisms developed within the industry participate slightly in absorption of the knowledge from the OPV. Thus, our proposition 1 is not confirmed.

If we notice that, at the certain point of time, wineries leaders are expecting information about markets, they are also looking for other types of information. Hence, they develop a number of informal exchanges with various actors of the industry. These exchanges can be established from information spread by the OPV, which appear as a low signal according to Ansoff (1975). In the facts, there are flexible and fluid relationships which are established spontaneously between individuals without being structured or advertised by one or several organizations. Wineries leaders express a need to exchange information informally with actors from their close environment like for example suppliers, distributors, business people and customers. According to Zahra and George (2002), these informative processes correspond to the concept of the company's "experience". Referring back to the verbatims, it seems that interactions with actors upstream and downstream of the production chain have an important role to play in the construction of the representations of the company.

"I had a discussion with my supplier. He should know..., there are studies and clients have tried this product last year" (Leader 1).

"I have a good feeling with my distributor of material, it works well with him. Every time there is a new technology on the market, I'm one of the first who can try it. It is this relationship that makes things move forward. I think it is really important, because the technique of rosé production is always evolving" (Leader 7).

"We sometimes ask customer to taste and to tell us what they think. We make tries, examples; it is not because the product seems ok for us that customers will buy it. It is important to stick to the reality of the market" (Leader 7). 
"We do not have formal meetings with our sell people, but we try to see them at least one or two times per year, to taste the new millésime. It is not especially easy to have them all at the same time, but we try" (Leader 1).

Wineries leaders are sensitive to the information concerning everyday life problems, information obtained through relationships with others actors in the industry and information reflecting concrete elements related "to the business field". The difference of attention between "local" information and more "global" information from the OPV can be explained by its applicability in the working context of the actors. Indeed, they give a large importance to their customers' requests and to their competitors' practices. Thus the potential of knowledge absorption by wineries depends on their own experience of the business field and of the relationships maintained with actors of their environment. The proposition 2 is confirmed.

\section{Discussion}

Our research presents limits inherent to the methodology used as well as to the qualitative approach adopted. Thus it is possible to exploit different tracks and refer back to other inquiries systems to capture the complexity of the studied phenomenon. The studied cases offer only one illustration of the possible knowledge appropriation processes when a company is exposed to different business intelligence systems. Furthermore, the study suggests results at a certain point of time in companies' history. It does not allow having longitudinal view of the evolution of behaviors over time. The results also have no claim to be transposable for the other activity sectors. However, our results offer an extension of the existing empirical knowledge on the business intelligence processes related to the study of the absorption capacity of the investigated wineries.

Therefore in reference to the theoretical model of ACAP used in this research, we make two main observations. First of all, the social mechanisms of integration set up by the OPV to spread information and sector-based knowledge to their members do not have a positive influence on the absorption developed by these members. Our results contradict the conclusions of researches conducted by Zaheer and Beautiful (2005), Kogut (2000), Reagans and McEvely (2003) or Zahra and George (2002). Several points need to be raised concerning the interpretation of this result. The notion of companies' network, as it appears in our study, differs on a structural plan from how it was often studied in the empirical studies of the inter-organizational absorption capacity. Indeed, the studied network is a "federation" and has not the same structural properties as a network created in a deliberated way by companies in a strategic alliance for example. In our context, wineries are part of pre-existent networks depending if they produce AOC or IGP wines. They thus use social mechanisms of integration which are not the result of a joint mode of coordination. The passive character of this business intelligent system indicates little commitment from wineries manager in the process of collecting, distributing, sharing and memorizing of the information. They perceive the information from the OPV, as a support and secondary activity far from their immediate concern.

On the other hand, the experiences made by wineries with key actors of their environment (customers, suppliers, competitors, etc.) represent informal processes of business intelligence. Results of our investigation show a positive influence on the capacity of wineries to absorb the information collected as described above. This is related to the researches of Zahra and George (2002) on the positive influence of the company's "experience". There are two major elements which allow the understanding of the predominance of this business intelligence system over the other one.

At first, this system does not require a specific activity but is directly related to the current relationships wineries leaders have with economic partners. In other words, the coordination processes of the industry's economic activity appear as an opportunity to analyze its possible evolution. Unlike the business intelligence system related to the social mechanisms of the OPV, this system is part of an everyday agenda of the actors and does not require planning additional sequences. These comments join the theories of knowledge creation which present dialogues, exchanges and interactions between the members of a working team as essential elements of the processes of sense construction (Hargadon, 2002). The coordination can then be made by regular meetings or when the need is expressed.

Secondly, these business intelligence processes realized within a network are developed by wineries with actors having a certain similarity (at the level of the business culture, the geographical business sector, economic and organizational issues, etc.).This observation thus confirms the conclusions revealed by Lane and Lubatkin, (1998) which underlined that the level of similarity between companies favors the appropriation of knowledge exchanged between them. Our empirical study allows going further on this point: besides the appropriation of the exchanged information, these similarities tend to structure the business intelligence network by which they are going to be exchanged. In other words, the similarity between companies appears as an influential factor both on the structural and on the cognitive dimension of the business intelligence system. 
Therefore wineries leaders have practices of information usages which complete the existing business intelligence practices in the Provence wine industry. They adopt a business intelligence approach based on daily and informal relationships with actors close to them and which have a consistent part in their work agenda. Lane and Lubatkin (1998) showed that the absorption is a function of the similarity with the organism which transfers the information. We observed that even if similarity with this organism was low (OPV), the absorption could happen due to a combination of information with information coming from the company's "experience" with other actors in the environment.

Wineries' leaders have to deal with lots of information coming from professional organisms of the Provence wine industry. Our study shows that by developing autonomous, but closely related business intelligence systems, these professional bodies maintain a redundancy and participate in an informative profusion as perceived by the interviewees. This will lead to a dispersal of the means used in the industry.

The research puts in perspective that coordination should be established between professional organisms to co-develop information systems and business information systems. This pooling could decrease the number of information spread by the professional organisms and make a better use of resources used until then for autonomous business intelligence systems. It is not a matter of sharing all means but to specialize (in coordination with the others) the distribution of information according to the skills and missions of each organism. It could give rise to more active and more precise business intelligence systems. He putting together of certain means and the specialization on specific skills could be perceived as an added value for the actors of the industry, who would then see the quantity of distributed information being reduced.

\section{Conclusion}

In its initial acceptances (Cohen \& Levinthal, 1990), the model of ACAP considered that a company absorbed information in an identical way without taking into account its origin. Lane and Lubatkin (1998) revised this reasoning by specifying that, in the case of transfers of knowledge inter-firms, this absorption was influenced by the level of "similarity" between companies. Our research goes further on this perspective by showing that, with the aim to increase its absorption capacity, a company will be able to multiply and articulate information sources resulting from various organizations with which it will have a more or less important level of "similarity". Hence, the level of information and knowledge absorption cannot be explained by the cognitive, cultural or organizational properties of the transmitters of the information. It is maybe based on the capacity of the receiver to combine them, and to enhance the interpretations which can be made.

\section{Acknowledgements}

The authors would like to thank the Provence Alpes Côte d'Azur Regional Council and the Provence Wine Council for their financial support.

\section{References}

Amabile, S., \& Guechtouli, M. (2008). Veille et sélection de l'information: intégrer les acteurs dans le développement de filtres informationnels intelligents. Revue Finance, Contrôle, Stratégie, 11(3), 189-215.

Amabile, T. M. (1998). Inner Work Life: Understanding the Subtext of Business Performance. Harvard Business Review, May, 72-8.

Ansoff, I. (1975). Managing strategic surprise by response to weak signals. California. http://dx.doi.org/10.2307/41164635

Argyris, C. (1976). Single-loop and double-loop models in research on decision-making. Administrative Science Quarterly, 21(3), 363. http://dx.doi.org/10.2307/2391848

Arikan, A. T. (2009). Interfirm knowledge exchanges and the knowledge creation capability of clusters. Academy of Management Review, 34(4), 658-676. http://dx.doi.org/10.5465/AMR.2009.44885776

Avenier, M. J., \& Schmitt, C. (2007). Élaborer des savoirs actionnables et les communiquer à des managers. Revue Française de Gestion, 174, 25-42. http://dx.doi.org/10.3166/rfg.174.25-42

Blanchet, A., \& Gotman, A. (1992). L'enquête et ses méthodes: L'entretien. Paris, Nathan Université, collection sociologie 128 .

Bower, G. H., \& Hilgard, E. R. (1981). Theories of Learning. Englewood Cliffs, NJ: Prentice Hall.

Brown, J. S., \& Duguid, P. (1991). Organizational learning and communities-of-practice: toward a unified view of working, learning, and innovation. Organization Science, 2(1), 40-57. http://dx.doi.org/10.1287/orsc. 2.1 .40 
Charreire Petit, S., \& Durieux, F. (2008). Explorer et tester: les deux voies de la recherche. In Thietart, R. A. (Ed.), Méthodes de recherche en management (3rd ed.) (chapitre 3, pp. 58-83). Paris: Dunod.

Cohen, W. M., \& Levinthal, D. A. (1990). Absorptive capacity: a new perspective on learning and innovation. Administrative Science Quarterly, 35(1), 128-152. http://dx.doi.org/10.2307/2393553

Cyert, R., \& March, J. G. (1963). A Behavioral Theory of the Firm. Englewood Cliff: Prentice Hall.

Eisenhardt, K. M. (1989). Building theories from case study research. Academy of Management Review, 14(4), 532-550.

Flanzy, C., Masson, G., \& Millo, F. (2009). Le vin rosé. Edition Ferret.

Galbraith, J. R. (1974). Organization design: an information processing view. Interfaces, 4(3), 28-36. http://dx.doi.org/10.1287/inte.4.3.28

Grant, R. M. (1996). Prospering in dynamically-competitive environments: organizational capability as knowledge integration. Organization Science, 7(4), 375-387. http://dx.doi.org/10.1287/orsc.7.4.375

Gray, P. H., \& Meister, D. B. (2004). Knowledge sourcing effectiveness. Management Science, 50(6), 821-834. http://dx.doi.org/10.1287/mnsc.1030.0192

Hannin, H., Couderc, J. P., D’Hauteville, F., \& Montaigne, E. (2010). La vigne et le vin: mutations économiques en France et dans le monde. Collection les Études de la Documentation française, La Documentation française.

Hargadon, A. (2002). Brokering Knowledge: Linking Knowledge and Innovation. Research in Organizational Behaviour, 24, 41-85. http://dx.doi.org/10.1016/S0191-3085(02)24003-4

Henderson, R. M., \& Clark, K. B. (1990). Architectural innovation: the reconfiguration of existing product technologies and the failure of established firms. Administrative Science Quarterly, 35(1), 9-30. http://dx.doi.org/10.2307/2393549

Huber, G. P. (1991). Organizational learning: the contributing processes and the literatures. Organization Science, 2(1), 88-115. http://dx.doi.org/10.1287/orsc.2.1.88

Julien, P. (1995). New technologies and technological information in small businesses. Journal of Business Venturing, 10(6), 459-475. http://dx.doi.org/10.1016/0883-9026(95)00084-L

Kogut, B. (2000). The network as knowledge: generative rules and the emergence of structure. Strategic Management Journal, 405. http://dx.doi.org/10.1002/(SICI)1097-0266(200003)21:3<405::AID-SMJ103>3.0.CO;2-5

Lane, P. J., \& Lubatkin, M. (1998). Relative absorptive capacity and interorganizational learning. Strategic Management Journal, $19(5)$ 461 http://dx.doi.org/10.1002/(SICI)1097-0266(199805)19:5<461::AID-SMJ953>3.0.CO;2-L

Lane, P. J., Koka, B. R., \& Pathak, S. (2006). The reification of absorptive capacity: a critical review and rejuvenation of the construct. Academy of Management Review, 31(4), 833-863. http://dx.doi.org/10.5465/AMR.2006.22527456

Leonard-Barton, D. (1992). Core capabilities and core rigidities: a paradox in managing new product development. Strategic Management Journal, 13, 111-125. http://dx.doi.org/10.1002/smj.4250131009

Levitt, B., \& March, J. G. (1988). Organizational learning. Annual Review of Sociology, 14, 319-340. http://dx.doi.org/10.1146/annurev.so.14.080188.001535

Lewin, A. Y., Massini, S., \& Peeters, C. (2011). Microfoundations of Internal and external Absorptive routines. Organization Science, 22(1), 81-98. http://dx.doi.org/10.1287/orsc.1100.0525

Malhotra, A., Gosain, S., \& El Sawy, O. A. (2005). Absorptive capacity configurations in supply chains: gearing for partner-enabled market knowledge creation. MIS Quarterly, 29(1), 145-187.

March, J. G. (1991). How decisions happen in organizations. Human-Computer Interaction, 6(2), 95. http://dx.doi.org/10.1207/s15327051hci0602_1

March, J., \& Simon, H. A. (1958). Organizations Wiley. New York, NY.

Miles, M. B., \& Huberman, A. M. (2003). Analyse des données qualitatives (2nd ed.). De Boeck Université, Bruxelles. 
Mitchell, V. L. (2006). Knowledge integration and information technology project performance. MIS Quarterly, $30(4), 919$.

Nelson, R., \& Winter, S. (1982). An Evolutionary Theory of Economic Change. Cambridge: Harvard University Press.

Nonaka, I. (1994). A dynamic theory of organizational knowledge creation. Organization Science, 5(1), 14-37. http://dx.doi.org/10.1287/orsc.5.1.14

Nystorm, P. C., \& Starbuck, W. H. (1984). To avoid organizational crises, unlearn. Organizational Dynamics, 12(4), 53-65. http://dx.doi.org/10.1016/0090-2616(84)90011-1

Ocasio, W. (1997). Towards an Attention-based View of the Firm. Strategic Management Journal, 18, Special $\begin{array}{lll}\text { Issue, } & \text { Summer, } & 187-206 .\end{array}$ http://dx.doi.org/10.1002/(SICI)1097-0266(199707)18:1+<187::AID-SMJ936>3.3.CO;2-B

Reagans, R., \& McEvily, B. (2003). Network structure and knowledge transfer: the effects of cohesion and range. Administrative Science Quarterly, 48(2), 240-267. http://dx.doi.org/10.2307/3556658

Simon, H. A. (1969). The Sciences of the Artificial. Cambridge Management Review, 18(2), 21-33.

Stalk, G. (1993). Vaincre Le Temps: Reconcevoir L'entreprise Pour Un Nouveau Seuil De Performance. Dunod.

Todorova, G., \& Durisin, B. (2007). Absorptive capacity: valuing a reconceptualization. Academy of Management Review, 32(3), 774-786. http://dx.doi.org/10.5465/AMR.2007.25275513

Tushman, M. L., \& Nadler, D. A. (1978). Information processing as an integrating concept in organizational design. Academy of Management Review, 3(3), 613-624.

Van Den Bosch, F. A. J., Volberda, H. W., \& De Boer, M. (1999). Coevolution of firm absorptive capacity and knowledge environment: organizational forms and combinative capabilities. Organization Science, 10(5), 551-568. http://dx.doi.org/10.1287/orsc.10.5.551

Van Maanen, J. (1983). Qualitative Methodology. Beverly Hills, CA: Sage Publications.

Wacheux, F. (1996). Méthodes qualitatives de recherche en gestion. Economica, Paris.

Winter, S. G. (2000). The satisficing principle in capability learning. Strategic Management Journal, 21(10/11), 981. http://dx.doi.org/10.1002/1097-0266(200010/11)21:10/11<981::AID-SMJ125>3.0.CO;2-4

Yin, K. (2009). Case study research, design and methods. Applied Social Research Method Series, 5.

Zaheer, A., \& Bell, G. G. (2005). Benefiting from network position: firm capabilities, structural holes, and performance. Strategic Management Journal, 26(9), 809-825. http://dx.doi.org/10.1002/smj.482

Zahra, S. A., \& George, G. (2002). Absorptive capacity: a review, reconceptualization, and extension. Academy of Management Review, 27(2), 185-203.

\section{Note}

Note 1. In the Appendix, the reader will find a summary table of abbreviations used in the article.

\section{Appendix}

Table 1. List of abbreviations

\begin{tabular}{llll}
\hline AOP & Protected label of origin & CP & Côtes de Provence \\
\hline IGP & Protected geographic indication & CVP & Coteaux varois en Provence \\
\hline OPV & Professional wine organizations & CAP & Coteaux d'Aix-en-Provence \\
\hline CIVP & Provence Wine Council & & \\
\hline
\end{tabular}

